\title{
Research on Mo Yan's Novel under the Perspective of Nobel Prize in literature
}

\author{
Ping Li \\ Heihe University \\ Heihe, China 154399
}

\author{
Yu Zheng \\ Heihe University \\ Heihe, China 154399
}

\author{
Zhichun Zhu \\ Heihe University \\ Heihe, China 154399
}

\begin{abstract}
Mo Yan, a Chinese writer, won the 2012 Nobel Prize in literature. The committee said, Mo Yan "combined magic realism and folklore, history and contemporary society together", which was good news. Mo Yan built a unique subjective world of feelings. His abstract narrative and unfamiliar process constituted transcendental world with mysterious object, which has an obvious "pioneer" color.
\end{abstract}

Keywords—Nobel Prize in literature; Chinese writer Mo Yan

\section{INTRODUCTION}

The Chinese people have Nobel Prize complex. Actually not only the Chinese, Don't people in every country want to get this award? Anyhow, if someone gets the award, he gets certain affirmation. In that field, he must be in top-level and do outstanding contributions. However, China, known as the ancient civilizations, in the history of the Nobel Prize, is somewhat embarrassed.

\section{ACCUMULATION OF WRITERS IN NOBEL PRIZE IN LITERATURE}

Many Chinese writers have won Nobel Prize like TsungDao Lee and Chen Ning Yang and latter owners, including Yuan Tseh Lee in Taiwan. Although they are Chinese people, we are somewhat uncomfortable when saying these names. On one hand, the Chinese people continuously create miracles in scientific research in practice and we all know the Chinese is one of the cleverest nations in the world. However, we are always lack of a little in the leading scientific research of the world. It is said that the biggest possibility for the Chinese people to win Nobel Prize is artificial synthesis of bovine insulin. However, they missed that chance, leaving a lifelong regret. At that time, China was still in the turbulent period of the Cultural Revolution. Even they feel regretful and should reflect, their spirits to the still were in the upper hand to the capitalistic Nobel Prize. Intellectuals and knowledge are in a tight spot at that time because intellectuals and scientist are regarded as Stinking Old Ninth. The more knowledgeable they are, the more reactionary they are. Just think, even at that time they really took the Nobel Prize, it was only a reactionary

Fund project: Comparative research on works of Herta Muller and Mo Yan under the perspective of Nobel Prize in literature(No. 13C033), sponsored by Heihe university youth research talent support plan. academic authoritative material to criticize capitalist. After the reform and opening up, we understand the value of the Nobel Prize, knowledge and intellectuals. But it was too late. In the top scientific research field of the world, we don't know how far we are left behind by the times. if we are left behind in something, we need to spend efforts of generations to catch up. We are chasing the trend of the world. Scientists in other countries are constantly awarded and constantly create new research achievements, but looking at our science, we are shamed feel stressed. We believe that Chinese scientists can win the prize some day, the earlier the day comes, the better it is.

\section{The MeAning of BeING AwARDED}

On the problem of Nobel Prize, the Chinese people give too many politics meanings to it, which is a fast knot. The politics meanings of the Nobel Prize in natural science may be not obvious. But in terms of Nobel Prize in literature and peace, it is too distinct. The Chinese people are object to award Nobel Prize in peace to leaders of certain countries or famous international persons, including some of the figures we can't accept or related to China, such as the Dalai Lama and so on. What we are confused is why the money left by Nobel, a Swedish scientist who researches explosive, should award to politics people, why should it involves in politics. This award is international. Because of the differences of state systems and ideology they have totally different political rights and political criterion. Something seeming right in one country may be wrong in another country. The Nobel Prize means certain affirmation, praise and encouragement, so we must make the western value and political criterion be received by many countries. Such Nobel Prize is interference to politics of countries. For example, Dalai Lama wants to separate Tibet from China and makes Tibet highly autonomous, which is a provocation to the Chinese homeland security. Awarding Dalai Lama Nobel Prize in peace means encouraging such separation, which should be blamed and objected by Chinese people. 


\section{WORLD VALUE OF BEING AWARDED}

It is good news for Chinese people that Mo Yan won Nobel Prize. But in a sense, it is embarrassed. At present, we just consider it as it stands. We appreciated it they affirm our achievements in literature and award the prize to Chinese writer. However, if they award Nobel Prize in peace to the one who hurts our Chinese feeling and Chinese benefit and interferer Chinese internal affairs, we should fight back resolutely. They are totally two things. It must be unambiguous in terms of principle.

Nobel Prize was given to the local Chinese finally, and the Chinese was in a low profile as his name "Mo Yan". Some comments online said that Mo Yan won the Nobel Prize in literature injected a vaccine for vaccinia to the ideas of the 1.3 billion Chinese people and therefore Chinese people never felt self-abased and anxious when it came to the Nobel Prize. As the saying goes home is unfortunate while poetry will fortunate. At the moment, the revival of China just is around the corner, but the contemporary Chinese literature is in low ebb. Mo Yan's prize was a boost undoubtedly and promoted the influence of Chinese contemporary literature among Chinese people and inspired great creative passion of "literary youth" to create Chinese literature.

\section{RESEARCH ON THE IMAGES IN WORKS}

The author intentionally read Mo Yan's classic novel Big Breasts and Wide Hips when he won the Nobel Prize in literature and felt that Mo Yan's works was just like a diamond in rough. The shell is rich, lush, exuberant vitality of the land in the northeast countryside of Gaomi described by beautiful languages. The structure is using almost ridiculous fantasy stories to show unwieldy and tenacious survival life impulse among hundred years of turbulence in China. The quality is using a true universal value to expose ugliness and evil of reality. Reading his novel was just like holding a piece of warm and pure jade, what caught my eyes is beauty of combined Chinese characters, what impressed in heart is the shock after seeing the objective description of good and evil and finding the spiritual impetus for Chinese nation to survive for five thousand years. The impetus like a piece of jade, which represented desire to survive, yearning for reproduction and positive attitude of life.

Jade is the material for our ancestors to crave totem at the very beginning of civilization. Shapes of the totem include frog, snake, fish, turtle and bear. Common characters of these animals are strong survival ability and high reproduce ability. Big Breasts and Wide Hips objectively shows vitality life of common people under small-scale peasant economy in China. In the novel, Shangguan Lu looked forward to giving birth to a son to perpetuate our families but she has seven daughters. To fulfill this dream and avoid evil eyes of her parents-in-law, she has relations with a Swedish minister Maloja and gives birth to Shangguan Jintong. Apart from the idea of preferring boys to girls, we can see strong will to life just from her determination to have a son. The will comes from natural animal totem, Nüwa and the legend Avalokitesvara sends boy to family. They are impressed in the soul of the nation including survival and reproduction, life and growth in nature as well as tenacious struggle. The Chinese nation survived various difficulties relying on hundreds of thousands of mothers like Shangguan Lu with inexhaustible uterus and breast milk. Exactly the struggle for survival and reproduce inspired the minds and determination of Chinese nation to fight bravely.

The birth and bring up showed selfless and fraternal love of a mother. The male in Shangguan Lu's family were dead of the Japanese invasion. She brought up the eight children and her grandchildren even re-grand children constantly by herself. From Anti-Japanese War to national liberation to Cultural Revolution, Shangguan Lu brought up more than 16 children in the novel according to the author's rough statistics, which reflected the tragic life of contemporary Chinese women in the bitter years from the side. What's more is celebration of her selflessness and non-complaint. In the novel, the writer frequently spent pen and ink on describing and praising women's breasts because the breasts were swaddling clothes for babies, reliance for life and the symbol of maternal love. Under the turbulent social conditions, Shangguan Lu protected her babies with intelligence and wisdom and fed her babies with sheep milk. Facing judgment in Cultural Revolution, she fought with gritty eyes and firm deny. In her eyes, children were the impetus for life and faith. While in the Children's eyes, she was peaceful reliance and the harbor of home. This kind of instinctive maternal love was the most plain, real and great. It was represented objectively in Mo Yan's novel, just like peeled the skin of a piece of jade, showing refreshing light.

\section{BRILLIANCE OF HUMANITY IN WORKS}

In books of Mo Yan, there is brave and courageous, fiery and crazy love. From faithful persistent and fearless we can find undertaking of Chinese man, steadiness of Chinese women with life and death accompany and sharing weal or woe together. At the same time, we noticed love was powerless, and weak and dismal in reality. In terms of the love between Shangguan Lingdi and Niaoer Han, Shangguan Lingdi became a bird fairy after Niaoer Han died. The love between Shangguan Pandi and American pilot Babbitt died in the cave where the hand grenade exploded. The end of love between Sha Zaohua and Sima Liang was her jump from a building because he didn't accept her love. All of these were incomplete. The sad love stories made people sigh with regret on fugitive life and incomplete love. Just like jade in hand, the jade itself was beautiful but there were some spots or cracks or color changes, on which people felt sorry and distressed. Maybe exactly these incomplete loves were somewhat confused and complex after reading, but when we turned to real life, we also felt that to be with the lover forever was simple in words but hard in act.

North east countryside of Gaomi lies in Shandong province, where was the home of Chinese traditional culture Confucianism. Confucianism stressed on restricting human nature by ethics. The so-called keeping heavenly principles and destroying human desire was decided by the reality living near without interaction under the small-scale peasant economy. But in the book Big Breasts and Wide Hips, what we saw was breaking through moral codes, the liberation of human nature and the romantic catharsis of free mind. The instinct struggle to rub survival and reproduce ability promoted 
characters performed incisively and vividly. Sima Ku, Sun Buyan, Niaoer Han and Jiang Liren, their possessiveness was almost greedy to women, their desire to power was nearly obsessed. E can also find the rakish men were energetic to kill enemy and serve the country. The pen of Mo Yan was like a forbidding mirror, reflecting merits and short comes of men clearly to readers, and cleaned all the thought torment which retrained people. Of course, the natures such as devoting oneself to the country, the courage to face what he did and determination were the inspiration given to contemporary men in the novel. Meanwhile, we also felt ashamed for their behaviors such as preempting the reproductive rights and possessing women to vent selfish desire. Just like we appreciate and collect jade, what we really enjoyed was the feel and it was the peace of mind and cultural nurture rather than hiding the jade or waiting for the opportunity to gain a windfall or falsification, using shoddy goods for quality goods, which was blasphemy to both jade and culture.

Along with the praise there were defamation and fling abuses, especially for the first Chinese writer Mo Yan who won the Nobel Prize in literature. There were endless critics to Mo Yan online. The netizen said Mo Yan's novels were starknaked and his description on sex was too direct, which didn't respect women. As far as the author's concerned, these were representation of blundering psychology of Chinese people and their comments on Mo Yan's novels were superficial. Mo Yan's reflection on Chinese history, his analysis on humanity, the helplessness and struggles showed in characters in the torrent of history, the praise for life as well as the fantastic and dark complaint to reality reflected by stories of the magical realism, opened up a new era in the history of Chinese contemporary literature belonging to Mo Yan. Thousands of words can't hold a candle to the essence of Mo Yan. Only people who understood him can realize it clearly, just as diamond in rough in Kunlun Mountain, can only be met by nice ring.

Mo Yan said, the development of literature can just rely on an award. The true impetus is the desire to get rid of darkness and longing for brightness. Writing for award will go opposite. He said, the title "Most likely to win the Nobel Prize for literature" once made him miserable. "If you hate someone, just say he is the most promising writer being awarded the Nobel Prize in literature". While he admitted that the prize made him realize that he had some misunderstanding to Nobel Prize. The first criterion for the prize should be the literary achievements of a writer and then the others.

\section{REFERENCES}

[1] Zhang Zhizhong. To Mo Yan's novel[J]. Literary Review, 2013(1): Page 88-95.

[2] Fan Baoling. An Narrative Analysis on Mo Yan's Novel[J]. Journal of Quanzhou Normal University, 2007, 25(5): Page 111-115.

[3] Kong Yanmei, Wang Jingrong, Song Fei. An analysis on the scenery features in north east countryside of Gaomi in novels of Mo Yan. [J].home of Drama, 2014(11): Page 270-270.

[4] Wang Yu. Deconstruction and reconstruction of creation concept in Mo yan's novel[D]. Yanbian University, 2011. 